\title{
A população lésbica em estudos da saúde: contributos para uma reflexão crítica
}

\author{
The lesbian population in health studies: \\ contributions for a critical reflection
}

António $M$ anuel $M$ arques ${ }^{1}$ João $M$ anuel de Oliveira ${ }^{2}$ Conceição N ogueira ${ }^{3}$

${ }^{1}$ Escola Superior de Saúde Instituto Politécnico de Setúbal. Campus do IPS Edifício da ESCE 2914/503, Estefanilha. Setúbal Portugal

antonio.marques@ess.ips.pt

${ }^{2}$ Centro de Psicologia,

Universidade do Porto.

${ }^{3}$ Centro de Psicologia,

Faculdade dePsicologiae

Ciências da Educação,

Universidade do Porto.

Abstract For decades, lesbian sexuality was associated with pathology in theattitudes to and practices of health sciences and psychology. During the twentieth century that position changed gradually. This article analyzes these changes in a theoretical reflection on the domain of lesbian health, dominated by heteronormative and heterosexist concepts and practices both in research and in health care. By means of a critical contextualization of the literature, specific health needs of lesbians wereidentified and theinterventions of health care professionals and services were questioned. Specific concrete actions are proposed in the fields of health promotion and in the eradication of discrimination and inequality in health care.

Key words Lesbians, Health, Sexuality, Health care services
Resumo Durante décadas, no pensamento e nas práticas das ciências da saúde e da psicologia a sexualidade lésbica foi associada à patologia. Ao longo do século $X X$, este posicionamento modificou-se. Estetrabalho analisa essas mudançasnuma reflexão teórica focada no domínio da saúde das lésbicas, no qual predominam as concepções e práticas heteronormativas e heterossexistas, tanto na investigação como na prestação de cuidados. A través de uma contextualização crítica da literatura, identificamos as necessidades específicas das lésbicas, questionamos as intervenções dos profissionais e serviços de saúde e propomos medidas de ação concretas de promoção da saúde e de erradicação da desigualdade e discriminação.

Palavras-chave Lésbicas, Saúde, Sexualidade, Serviços de saúde 
Introdução: uma curta viagem pela despatologização da homossexualidade

Este artigo visa produzir uma contextualização crítica sobre as mudanças conceituais no tratamento que a literatura relevante dos estudos faz sobre a saúde das lésbicas, analisando com maior detalhe o período pós-despatologização da homossexualidade, Todavia, iniciamos estetexto com uma breve incursão pelo período em que a homossexualidade era patologizada. N este trabalho não pretendemos fazer uma revisão exaustiva da literatura, antes temos como intenção percorrer analiticamente esta investigação, evidenciando os seus principais contributoserefletindo criticamente sobre esta produção. Desta forma, o presente texto constitui uma contextualização critica da literatura sobre a saúde das lésbicas.

Nos intensos debates que marcaram as ciências no século XX devem, no contexto desta contextualização crítica, ser salientados dois: a mudança operada pelo conceito de gêner $0^{1}$ ea atenção prestada às sexualidades ${ }^{2}$. Em ambos os casos, estes conceitos vieram operar uma mudança na atenção conceitual dada às sexualidades não heterossexuais e às mulheres.

É nesta linha de pensamento que a despatologização das homossexualidades ganha saliência. Se, por um lado, as disciplinas das ciências da saúde discutiram muito detal hadamente as questões das sexualidades desde o século XIX, nome adamente nos domínios da sexologia e mais tarde da psicanálise, esta temática passou a integrar as preocupações de praticamente todas as vertentes epistemológicas. Assumimos que o estudo da sexualidade implica considerar que esse domínio ocupa muitas outrasáreas ci entíficas eque mesmo que um estudo esteja localizado em de terminada disciplina ${ }^{3,4}$ é necessário salientar a interdisciplinaridade desta produção.

Os estudos sobre sexualidade ${ }^{5-7}$ têm elucidado os modos como determinados comportamentos sexuais foram encarados como identidades, pela sexologia do século XIX e princípio do XX, e como essas identidades foram vistas como descritores dos indivíduos, criando categorias sociais, como sejam o homossexual ou a lésbica. Asmúltiplas perspectivas implicadas nestes estudos têm vindo a salientar a importância deposicionamentosquetenham em linha deconta os direitos humanos destes grupos, dado se rem histórica esociologicamentelesados nos seus direitos, tal como aconteceu com as mulheres ${ }^{8}$. Desta forma, há uma preocupação com a situação social de opressão sobre estes grupos e uma aspiração em desenvolver estudos quecontextualizem e permitam situá-los ${ }^{9}$ numa ótica de conhecimentos emancipatórios que possam contribuir para uma erradicação da opressãa ${ }^{10}$.

Foucault ${ }^{11}$ analisou os modos como as regulações normativas criaram determinados sujeitos sexuais, como o homossexual ea lésbica. Assim, no seu entender, o foco do processo éa constituição sócio-histórica das categorias sociais e o modo como elas correspondem a processos normativos e reguladores dos indivíduos ${ }^{12}$. Assim, Foucault ${ }^{11}$ mostrou como a sexologia criou a figura da homossexualidade no século XIX.

Apesar da proliferação de discursos históricos e antropológicos que atestam a existência de comportamentos sexuais não normativos noutras culturas e com uma continuidade histórica, os trabalhos supracitados questionaram diretamente a plausibilidade de considerar, por exemplo, a sodomia como equivalente funcional da homossexualidade. Pelo contrário, 0 autor ${ }^{11}$ elucidou como a sodomia não só permitiu a severidade penal, como manteve uma tolerância vasta em relação a uma multiplicidade de comportamentos. Ou seja, nem todos os comportamentos concebidos hoje como homossexuais seriam antes punidos num quadro de referência sodomita. A emergência da homossexualidade permitiu separar estes comportamentos de uma moldura penal e passá-los para o plano da ciência e da medicina. Assim, a homossexualidade começa por ser considerada no quadro de uma (homo)sexologia ${ }^{13}$, a qual, apesar de se ter esforçado para retirar a homossexualidade da alçada da justiça penal, passa a submetê la a uma análise da esfera da ciência. Tal transição implicou que a homossexualidade passasse a ser vista como patologia, pelo que deveria ser diagnosticada, estudada, escrutinada e curada.

Estas mudanças também são mencionadas em relação às lésbicas. Se no século XIX, a sexologia começa a descrever a homossexualidade, esta é, em geral, tornada mais visível no caso dos homens do que das mulheres ${ }^{3}$, por questões ligadas ao cruzamento entre orientação sexual e gênero. Assim, pretendemos mapear o pensamento da sexologia em relação à concetualização das sexualidades lésbicas.

No caso da sexologia, um dos modelos para pensar as lésbicas foi o da inversão sexual como mostra $\mathrm{H}$ alberstam ${ }^{14}$. A inversão descreve características atribuídas a um sexo que aparecem em indivíduos de outro sexo. Este conceito foi usado para descrever mulheres masculinizadas ou homens efeminados que a sexologia da época foi 
associando à orientação sexual. Ou seja, trata-se de um processo que cruza sexualidade e gênero, hibridizando-0s, surgindo assim a inversão sexual. A invertida emergecomo descrição de uma mulher com um desejo por pessoas do mesmo sexo ea quem são reconhecidas características de masculinidade ${ }^{15}$. Este termo veio, contudo, contribuir para estancar a diversidade e a especificidade de outros termos para descrever as lésbicas como as "tríbades", "hermafroditas" e "travestis" ou as "mulheres masculinas"14. No princípio do século $X X$, assiste-se, em toda a Europa, à medicalização das subculturas sexuais emergentes, bem como ao reforço do poder disciplinar das correntes higienistas na medicina e na sexologia médica, assumidas enquanto instâncias definidoras de identidades ${ }^{14}$.

Ora, é preciso igualmente não deixar fora de vista a produção do gênero enquanto instância fundamental para definir estes processos. A história do gênero que Laqueur ${ }^{16}$ apresenta permite perceber que a inversão apresenta uma história interessante do ponto de vista do gênero. Para Laqueur ${ }^{16}$, há dois modelos dominantes nas concepções do gênero: a teoria deum sexo eo de duas espécies. No primeiro (... ) "dominanteno pensamento anatómico por dois mil anos, a mulher era entendida como um homem invertido: o útero era o escroto feminino, os ovários eram os testículos, a vulva era o prepúcio e a vagina era o pênis"; no modelo posterior de duas espécies, homem e mulher são tidos como opostos e assentes na total diferença sexual como forma de pensar os corpos, ou seja, é do dimorfismo sexual queemerge a sua concepção. Pareceencontrarse uma ressonância do pensamento do modelo unissexual no modelo da inversão sexual. Repare-se, por exemplo, no caso da "tríbade", figura que põe em causa tanto a ordem de gênero, pela associação a atributos ativos, questionadores da posição submissa do feminino, bem como afronta à ordem heterossexista inquestionável, por um desejo pelo mesmo sexo ${ }^{17}$. Este temor e duplo questionamento estendem-se também à imagem da "sáfica". Aproveitando a história de Safo, a poetisa de Lesbos, os Séculos XIX eXX produzem toda uma categoria assente no safismo. Tido como equivalente ao chamado lesbianismo (que deriva da ilha grega de Lesbos), o safismo (de Safo) é usado como categoria identitária para descrever uma mulher cujo alvo dos seus comportamentos sexuais são outras mulheres.

No entanto, a sexologia da época conhecia poucos casos de "safismo", documentando-se em descrições de casos clínicos, jornais, relatos auto- biográficos e ficção ${ }^{18,19}$ e mantinha-se, assim, arraigada aos pressupostos genderizados da época, pois as mulheres eram sempre situadas num patamar inferior ao dos homens, até nos textos da sexologia moderna. Freud é um bom exemplo desta situação, mantendo um discurso de subalternização das mulheres, por exemplo, no conceito de inveja do pênis. De acordo com Weeks ${ }^{20}$, para Freud, a perversão era parte integrante das sexualidades de todos e todas e não uma característica de uma população específica, o quetorna a explicação freudiana emancipatória, à época, para um pensamento sobre a homossexualidade. Estas explicações permitem, contudo, uma deslocação do objeto "lésbicas e homossexuais" para fora da al çada da estrita biologização ${ }^{21}$.

A continuidade desta geneal ogia da despatologização leva-nos a considerar o trabalho de Kinsey et al. ${ }^{22}$, que se dedica ao estudo sistemático por questionário da diversidade sexual da população americana e que evidencia que 2 a $6 \%$ das mulheres dos EUA se definia como exclusivamente homossexual. As escalas deKinsey, contudo, introduziram um importante contributo metodológico, vendo a orientação sexual como um contínuo, em vez de unidades discretas. Para tal contribuiu a visão de Kinsey, assente numa bissexualidade humana geral com cambiantes universais ${ }^{5}$. Todavia, na mesma época em que Kinsey realiza estes importantes trabalhos, em 1952, a Associação Americana de Psiquiatria está a criar a categoria diagnóstica homossexualidade no Diagnostic and Statistical M anual of M ental Disorders (DSM). Alimentado por trabalhos que ligavam a homossexualidade à desregulação hormonal ou a determinadas características comportamentais, a homossexualidade passa a ser "tratada" recorrendo a terapias electroconvulsivas e a outras práticas psicoterapêuticas?.

É nos anos 50 que o movimento social pela defesa dos direitos das pessoas homossexuais começa a surgir. Primeiro com as organizações homófilas, como a M attachine Society ou as FiIhas deBillitis (nosEstadosUnidos) e depois com uma expressão pública mais forte, após a revolta de Stonewall, com os movimentos de libertação homossexuais e lésbicos.

É nesta altura que começa um movimento de profissionais nas áreas da psiquiatria e psicologia, por forma a remover a homossexualidade do DSM, de que são exemplos os trabalhos de Hooker $^{23}$ ou Hopkins ${ }^{24}$ sobre a personalidade lésbica, os quais tentaram mostrar que a orientação sexual, só por si, não constituía nenhum problema psicológico adicional. Após um con- 
junto de investigações, de literatura produzida e de um amplo debate ${ }^{25}$, a edição do DSM de 1973 já tinha abandonado a homossexualidade enquanto categoria diagnóstica.

É, pois, partindo desta introdução a uma ge neal ogia muito sucinta do modo como as ciências da saúde e a psicologia construíram a ideia de lésbica que passamos a aprofundar os olhares contemporâneos sobre esta questão. Olhemos para o modo como as ciências da saúde investigam a questão da saúde das lésbicas após a despatologização da homossexualidade e como essas mulheres se relacionam com a sua saúde e com os serviços e profissionais.

\section{As lésbicas e o universo da saúde}

Nas últimas duas décadas, o desejo de compre ender a influência do gênero e da orientação sexual na área da saúde tornou-se mais evidente, sobretudo na investigação e na academia ${ }^{26,27}$, mas também nas políticas públicas dos países ditos ocidentai $s^{28,29}$, como evidenciam os estudos de revisão sistemática da literatura internacional. Todavia, no conjunto dos estudos publicados em língua inglesa, de 1980 a 1999, acessíveis através da base de dados da M edline, sobre a saúde da população LGB, predominam aqueles que se referem à população gay e com uma ênfase esmagadora na temática das infeções sexualmente transmissíveis, especialmente pelo HIV ${ }^{26}$.

Existe al gum conhecimento acerca de necessidades de saúde não satisfeitas por parte das lésbicas. Há evidência, com base em estudos de meta-análise ${ }^{30,31}$ e com recurso a amostras probabilísticas ${ }^{32}$, de que as lésbicas estarão sujeitas a riscos acrescidos relativamente a várias patologias. Assinala-se, contudo, a presença de al guma controvérsia quanto à fiabilidade desses resultados e ao estabelecimento de uma relação direta com a orientação sexual, por influência de diversos fatores, constituindo-se, por isso, como um desafio $0^{33,34}$.

Um desses fatores, do domínio conceptual, diz respei to à diversidade de significados do termo e da categoria'lésbicas', o que não se coaduna com a exigência de consenso e estandardização dos grupos populacionais, essencial ao raciocínio epidemiológico, para a determinação segura, por exemplo, da incidência e prevalência de de terminada patologia ou problemática de saú$\mathrm{de}^{34,35}$. Sob a denominação categorizante de 'lésbica' reside a heterogeneidade das autoclassificações das participantes nos estudos, as quais po- dem incluir a identidade, a orientação do desejo e o comportamento sexual, os quais terão correspondência, ou não, entre si ${ }^{36,37}$.

É admissível que, por si só, ter experiências sexuais com outras mulheres não determine a assumpção de uma identidade exclusivamente lésbica, bem como nem sempre o desejo se concretize em atividades sexuais, como se verifica numa amostra representativa de norueguesas ${ }^{38}$. Por outro lado, haverá também que considerar a possibilidade da fluidez da orientação sexual ao longo do ciclo vital, manifesta em termos continuados ou episódicos, o que fará com que comportamentos heterossexuais antecedam (ou sejam antecedidos) dos homossexuais ou mesmo que coexistam num ou vários períodos da vida de uma mulher $32,36,37,39$. Os recentes estudos de Lisa Diamond ${ }^{40}$ sobre a fluidez sexual das muIheres mostram tanto a estabilidade como a mudança nas orientações sexuais, o que apela à reflexão e clarificação de pressupostos nas investigações, incluindo as da esfera da saúde.

A determinação da validade interna e externa dos estudos epidemiológicos focalizados na saúde das lésbicas representa outro dos fatores que justifica a necessidade de complexificação das práticas e do pensamento epistémico-metodológico. Os contextos sociais e relacionais pautados pela estigmatização das chamadas minorias sexuais não favorecem a divulgação da sua orientação sexual e, logo, a participação voluntária das lésbicas nesses estudos, dando lugar ao "viés da marginalização" 34 . Haverá, por isso, que admitir a forte plausibilidade de subestima de potenciais fatores de risco e/ou de proteção da saúde associados a essas mulheres e a impossibilidade de inferências seguras, por sub-representação e ausência de informações fidedignas e pelo recurso alternativo a amostras de conveniência ${ }^{33,34,41}$.

Do mesmo modo e pela precariedade e insegurança de dados, a validade externa de grande parte dos estudos também ficará comprometida, como evidencia o estudo orientado por uma perspectiva de indução analítica de $M$ alterud et al. ${ }^{34}$. Com grupos de participantes ou com amostras constituídas a partir de elevados níveis de incerteza edeindeterminação, ficarão tecnicamente vedadas as possibilidades de generalização do conhecimento epidemiológico à "população lésbica", bem como a sua comparação pertinente com a das "mulheres em geral" 34 .

Muito do conhecimento acumulado acerca das problemáticas e das vivências das lésbicas relacionadas com a saúde tem sido gerado a partir de "amostras de oportunidade" ou de conve- 
niência, envolvendo mulheresqueultrapassaram os receios de serem identificadas como lésbicas e que, em muitos casos, estão diretamente envolvidas em atividades cívicas de defesa dos seus direitos ${ }^{37,42}$. Ainda que legítimo e promotor de debate e reflexão e uma forma viável deiluminar zonas ocultas e de desinvestimento público eacadémico no contexto da saúde destas mulheres, esse conhecimento élimitado quanto à identificação de fatores protetores e de risco e à validação dos resultados encontrados ${ }^{34}$.

O rigor epidemiológico tem como finalidade servir a adoção das medidas de saúde pública que permitam el evar os níveis de saúde dos indivíduos e populações, mas, para isso, é essencial "mapear as frequências e a distribuição de doenças específicas" ${ }^{34}$. Com as condi cionantes associadas ao envolvimento das lésbicas nos estudos sobresaúde, essa finalidade fica seriamente ameaçada, bem como as intervenções focalizadas nas suas necessidades. Tal reforça a necessidade de aceitação de que, desde a caracterização das situações ao planeamento das intervenções, se considere que (... ) "a saúde atravessa a realidade social, o que requer teorias fortes que suportem as práticas inovadoras" ${ }^{43}$ e que os fenómenos de saúde e de doença não sejam encarados como independentes das condições de vida e dos fatores socioculturais ${ }^{28,44}$.

Apesar das dificuldades deste campo de estudo, cientes das particularidades contextuais e metodológicas, valorizaremos, num primeiro momento, as tentativas para identificar especificidades quanto à saúde e à doença das lésbicase, por fim, questionaremos o papel dos profissionais e serviços de saúde e salientaremos os desafios e os posicionamentos críticos que daí devem derivar.

Problemáticas de saúde eparticularidades das lésbicas

Num estudo de meta-análise, a partir de publicações compreendidas entre 1966 e 2005, King et al. ${ }^{45}$ procuraram evidência quanto à vulnerabilidade específica da população LGB em alguns domínios da saúde mental. Salienta-se dessa análise que o risco de tentativa de suicídio, de transtornos mentais, de abuso de substâncias e de dependências - incluindo a do álcool -, de de pressão e de ansiedade é mais elevado na população LGB do que na heterossexual. As mulheres bissexuais e lésbicas revelam um particular risco de dependência de álcool e substâncias ilícitas, enquanto os gays e homens bissexuais tenderão a realizar mais tentativas de suicídio.

Outros estudos parcelares geograficamente localizados sugerem que, por comparação com a população heterossexual, as pessoas LG terão um risco acrescido de sofrimento psicológico, ansiedade, depressão, ideação suicida e transtornos psiquiátricos ${ }^{46}$. Refiram-se os exemplos dos estudos de Sandfort et al., a partir da realização de entrevistas face-a-face a 7076 holandesas heterossexuais e homossexuais ativas, entre os $18 \mathrm{e}$ os 64 anos $^{47}$ e de Fredriksen-Goldsen et al., com base nos dados quantitativos recolhidos entre 2003 e2007 junto de uma amostra de 1496 lésbicas e bissexuais americanas ${ }^{48}$.

Esta tendência poderá não se aplicar a situações de grande severidade psiquiátrica, como mostra o estudo comparativo deH ellman et al. ${ }^{49}$, junto de duas amostras, uma de 63 adultos de ambos os sexos, autodefinidos como LGBT e outra, de controle, com 100 participantes, às quais foi aplicado um questionário de 161 itens. Por outro lado, segundo Skidmore et al., o sofrimento psicológico relacionado com a não conformidade face ao socialmente expectável produzirá mais sofrimento psicológico nos gays do que nas lésbicas ${ }^{50}$. A partir das respostas de 44 lésbicas e 60 gays americanos a escal as validadas os autores concluíram que as primeiras serão menos vítimas de ameaças e de assédio verbal, ainda que sua vitimização ao longo da vida possa ser mais acentuada. Tal reforça a necessidade de análises distintas em função do sexo, valorizando a subjetividade com que as pessoas de cada um deles vivencia a não conformidade e os efeitos em termos de mal-estar psicológico, bem como os seus efeitos ao longo do tempo, como também sugerem Balsam et al. ${ }^{51}$.

N os estudos da área da saúde mental, aludese, com frequência, ao consumo excessivo de álcool e à utilização de substâncias psicoativas, comportamentos que serão significativamente mais elevados na população LGB, sobretudo durante a adolescência ${ }^{30,52}$. Algumas investigações que comparam o consumo alcoólico de mulheres lésbicas eheterossexuais têm confirmado a maior probabilidade de ocorrência nas primeiras ${ }^{32,36}$, o mesmo acontecendo quanto ao uso de substâncias psicoativas ${ }^{32,36,42}$. No estudo de H ughes et al..$^{53}$ a comparação das respostas de 63 lésbicas e 57 heterossexuais americanas em entrevistas em profundidade é um dos estudos que corrobora as observações dos estudos citados.

A pesar de encararem como seguros os resultados obtidos por meta-análise, quanto à maior 
probabilidade de desenvolvimento de mal-estar psicológico, abuso e dependência de substâncias e de patologia mental nas pessoas LGBT, consideradas as particularidades de homens e de muIheres, King et al. ${ }^{45}$ sublinham a necessidade de clarificar as componentes desta vulnerabilidade potencial e os mecanismos envolvidos, nomeadamente com o contributo de estudos qualitativos. Todavia, a título hipotético, referem que a hostilidade, o estigma e a discriminação experienciados deverão ser fatores a considerar na análise ena tentativa de compreensão dosníveis mais elevados de morbilidade psicológica, identificados em múltiplos estudos e em vários contextos geográficos e socioculturais. Tal orientação epistémica emetodológica, segundo Ponterotto ${ }^{54}$, terá um nível elevado deadequação para evidenciar a subjetividade das vivências das pessoas e, assim, suportar investigações sobre saúde que potenciem a afirmação individual e coletiva e que sejam comprometidas com critérios de justiça social.

Esta recomendação para o aprofundamento das relações complexas entre os indicadores de saúde e de doença e a identificação de fatores protetores e de risco étambém referida quanto à problemática do cancro e do autoexame da mama nas lésbicas ${ }^{5,56}$

Com efeito, a literatura tem indicado que as lésbicas terão menores taxas deadesão à realização de mamografias de rotina, ao autoexame da mama ${ }^{55-57}$ e à citologia ${ }^{30,55,56}$, quando comparadas com as mulheres heterossexuais, dificultando a detecção precocededoença oncológica econtribuindo para maiores níveis de morbimortalidade.

As razões pelas quais as mulheres lésbicasjustificam a não adesão à mamografia não diferem substancialmente das apresentadas pelas heterossexuais. 0 estudo transversal conduzido por Aaron et al., envolvendo 1010 lésbicas americanas ${ }^{57}$, faz referência a desconforto, falta de motivação, desconhecimento acerca dos procedimentos, emoções negativas, como o receio dos resultados. Por sua vez, a tendência para a não adesão ao teste Papanicolau será influenciada pelas concepções erradas por parte de lésbicas que consideram existir menos risco de cancro cervical se não tiverem atividades sexuais coitais com homens, como dá conta um estudo que combina a utilização de grupos-focais equestionários junto de 101 lésbicas americanas ${ }^{58}$.

Para a compreensão e o aprofundamento do conhecimento nestedomínio específico, Wilkinson e Fish ${ }^{55}$ defendem que se evitem interpreta- ções lineares. As autoras chamam a atenção para as dificuldades de delimitação segura eindu bitável degrupos demulheres que, nas investigações, são categorizadas ou autoi dentificadas como lésbicas, como também aludimos de início, o que poderá levar à assumpção de que existe sobre posi ção exata entre comportamentos e identidade. Tal clarificação é essencial para a consideração dos fatores de risco associados à patologia mamária, como o excesso de peso, o consumo excessivo de álcool ${ }^{53}$ e, sobretudo, a nuliparida$\mathrm{de}^{59}$. Como sublinham $\mathrm{M}$ alterud et al. ${ }^{34}$, se, nas lésbicas, o risco aumentado de cancro na mama derivar, em grande medida, do facto de se reproduzirem menos do que as heterossexuais, será grave atribuir o mesmo risco àquelas que, sendo lésbicas, tiverem gravidezes a termo, pois recorre-se à identidade para assumir comportamentos e, logo, determinar a probabilidade de ocorrência de uma patologia com base numa suposição ideologicamentemarcada e restritiva, ou seja, na ideia que as lésbicas não se reproduzem.

No domínio da saúde sexual e reprodutiva, como apelam Goldstein ${ }^{39}$, Arend ${ }^{60}$ e M ercer et al. ${ }^{32}$, conviráter semprepresente a distinção necessária entre comportamento eidentidade sexual no que se refere, neste caso, à população lésbica. Esseprincípio será válido, nomeadamente, no acompanhamento de gravidezes e na prevenção do VIH ou em situações de seropositividade.

Quando ocorre uma gravidez numa mulher ou num casal de lésbicas, a comunicação e as rotinas dosprofissionaise serviçosorientam-se, tendencialmente, pela norma da heterossexualidade, como evidencia um estudo fenomenológico norueguês, com entrevistas a seis casais delésbicas ${ }^{61}$. Do mesmo modo, haverá uma tendência dominante para considerar a baixa probabilidade de ocorrência de transmissão do VIH entre mulhe res, assumindo-se, como faz o CDC (Centers for Disease Control and Prevention), que a soropositividade em tais casos se deverá a comportamentos heterossexuais prévios ou a comportamentos aditivos de risco por via injetável ${ }^{60}$.

Assim, a diversidade de comportamentos e modos de vida poderá levar a que não exista sobreposição entre identidade e comportamento lésbico ou heterossexual ${ }^{39}$. Qualquer que seja 0 seu número e proporção no conjunto de mulheres, são necessários e exigíveis procedimentos profissionais adequados que não se baseiem em pressupostos infundados como referiremos no item seguinte. 
Lésbicas e a sua relação com os serviços e os profissionais de saúde

Os níveis de qualidade dos serviços prestados pelos profissionais e instituições de saúde às mulheres lésbicas resultarão de um conjunto articulado de fatores relacionados com as particularidades e necessidades das utentes, a ação direta dos profissionais e o funcionamento dos serviçose, também, dos contextos socioculturais em que as interações ocorrem.

Vários estudos referem-se à menor procura dos cuidados de saúde por parte das pessoas não heterossexuais ${ }^{62}$, mas as informações disponíveis não permitem conclusões definitivas, devido aos baixos níveis de representatividade ${ }^{35}$. Todavia, a procura de serviços especializados em saúdemental tenderá a ser mais el evada por partede gays e lésbicas ${ }^{35,46,56,63}$, o que tem al guma correspondência com as necessidades específicas referidas no item anterior.

0 estudo de Bakker et al. ${ }^{35}$, baseado numa amostra de 9684 utentes holandeses com diversas orientações sexuais, aponta para uma taxa superior de utilização dos serviços de saúde por parte das pessoas LGB do que das heterossexuais, o que interpretam como mera diferença de comportamentos de procura de cuidados e não um indicador de piores condições de saúde. Por outro lado, no mesmo estudo, não foi encontrada relação entrea frequência da procura de ajuda profissional e o grau de confiança nos serviços, quando comparadas as respostas dos participantes com diferentes orientações sexuais, contrariando a ten dência sinalizada na literatura. $\mathrm{Na}$ interpretação dos investigadores, tal dever-se-á "ao clima de relativa tolerância social face à homossexualidade na Holanda, em comparação com outros países ocidentais" ${ }^{\prime 3}$.

A confiança nos profissionais de saúde ea sua relação com a revelação da orientação sexual por parte das pessoas LGBT tem merecido bastante atenção por parte dos investigadores. Em vários domínios da saúde e do bem-estar, para que os cuidados de saúde sejam centrados nas necessidades de cada utente e na sua individualidade, justifica-se a explicitação da sua orientação sexual, mastal poderá ser fonte de desconforto estress para as pessoas não heterossexuai $s^{30,35,62}$. As pessoas LG referem que, no contacto com os serviços de saúde, temem revelar a sua orientação sexual, por potenciais reações negativas, insensibilidade, retaliação, discriminação negativa ${ }^{30}$ e falta de sigilo no manuseio dos registos clínicos ${ }^{61}$.
A partir de uma amostra de norte-americanas maioritariamente brancas, o estudo de van Dam et al. ${ }^{62}$ evidenciou que as mulheres heterossexuais não sentiram necessidade de revelar a sua orientação sexual, pois assumiram que os profissionais de saúde são capazes de prever a identidade sexual dasutentes. Aslésbicas não evidenciaram este pressuposto, pelo que, com muito maisfrequência, revelaram voluntariamentea sua identidade sexual num atendimento clínico, mostrando acreditar que poderá ser vantajosa a afirmação da sua identidade perante os profissionais, por esta ser "um aspeto importante da sua saúde e bem-estar"62.

Tendencialmente, os serviços e os profissionais de saúde consideram que os utentes que os procuram são heterossexuai $s^{31,61}$. Como relatam Röndahl et al., em dois estudos qualitativos desenvolvidos na Suécia ${ }^{64,65}$, a heteronormatividade tem, necessariamente implicações importantes na qualidade das relações estabelecidas com aqueles que não se enquadram nessa categoria, por incumprimento dos princípios da igualdade e da justiça e da não satisfação das suas necessidades. Em termos genéricos, tem-se observado de que a heteronormatividade na organização dos serviços e nos esti los e conteúdos comunicacionais afetam negativamente a qualidade dos cuidados prestados a pessoas não heterossexuais, as quais se sentem incompreendidas, tratadas com desrespeito e receosas quanto às consequências da assumpção da sua orientação sexual $31,61,64,66$. Creem que os atendimentos baseados na heteronormatividade ocasionam equívocosno raciocínio clínico, os quais são sustentados por premissasquenão correspondem à realidade, aos estilos de vida, aos fatores protetores e de risco e às expectativas de utentes não heterossexuai $s^{66}$. As utentes lésbicas dizem receber informações e aconselhamento profissional que não Ihes são úteis nem adequados, deixando por cumprir apoios que correspondem às suas necessidades e vulnerabilidade particulare ${ }^{65,67}$.

Salienta-se, assim, a importância do momento e da forma de questionar os utentes acerca da sua identidade e, se justificado, dos seus comportamentos sexuais. No caso específico das lésbicas, estas precisam sentir que suas necessidades, preocupações e hesitações são compreendidas e integradas pelos profissionais com quem se relacionam, elementos básicos para o estabelecimento de relações colaborativas e de confiança ${ }^{62}$. Para estas utentes, o estilo de comunicação adotado pelos profissionais é um dos fatores 
mais importantes para a facilitação do diálogo e a discussão de temas mais íntimos e difíceis ${ }^{67}, 0$ quejustifica que estes desenvolvam competências relacionais e culturais específicas para cuidarem e atenderem utentes não heterossexuais.

Através da revisão de literatura, Bonvicini e Perlin ${ }^{66}$ identificam várias situações de comunicação e aconselhamento desadequados, quando é pressuposta a heterossexualidadedetodos osutentes ou sefaz uso exclusivo eimponderado de preconceitos acerca das particularidades de saúdedas lésbicas. Referem os domínios da saúde sexual e reprodutiva, como a contracepção, a acentuação excessiva das dificuldades de revelação da orientação sexual (coming-out), a não consideração da possibilidade de existirem ou virem a ter fiIhos, a presunção da existência de múltiplos parceiros/as. Por seu lado, alguns estudos ${ }^{55,65}$ sublinham que essa desadequação na comunicação também se expressa, frequentemente, de formas diretas e indiretas, nos suportes informativos nas zonas de espera, formulários, registos clínicos e materiais de educação para a saúde.

A formação é uma estratégia necessária para que exista efetivo investimento no desenvolvimento de competências profissionais. Para além do contexto específico da saúde reprodutiva, nas fases pré natal, do parto e do pós-parto ${ }^{64}$, a formação deve envolver todas as áreas de intervenção do setor da saúde e as diversas especializações profissionais, incluindo enfermeiros, médicos e técnicos de serviço socia|30,31,64,68,69.

0 desenvolvimento de competências profissionais e o desejo deliberado de estabelecer relações adequadas podem também ser expressos pela disponibilidade para considerar o contexto familiar e os elementos afetivamente significativos, para melhor conhecimento eenquadramento das utentes, e, quando desejado, envolvê-los nos cuidados prestados ${ }^{55,66}$. Essa estratégia, nomeadamente quando estão em causa adolescentes, pode concretizar-se na criação de grupos de encontro ou de autoajuda de familiares ou de figuras próximas de pessoas $L G^{69,70}$.

\section{Conclusões}

0 conhecimento aprofundado sobrea suscetibilidade à doença e a exposição aos riscos dificilmente será alcançado sem a consideração dos contextos sociais e culturais e dos níveis de acesso aos recursos que contribuem para a promoção da saúde e prevenção da doença. O s resultados epidemiológicos, por si só, são limitados para explicar os determinantes estruturais da saúde, pelo que o questionamento contínuo einsistente da causalidade e dos fatores de risco face à doença e a complexificação das análises são imperativos para a transformação positiva do setor da saúde, através da implementação de políticas e práticas efetivas ${ }^{28,71}$.

Para que a epidemiologia continue a produzir resultados e análises úteis e rigorosos, servindo para a fundamentação das tomadas de decisão na promoção da saúde e prevenção da doença, julgamos ser necessário reconhecer e adotar perspetivas críticas einterrogativas. A criação da "nova epidemiologia", orientada pela ótica feminista aplicada ao contexto da saúde, pretendeque o questionamento das práticas e concepções contemple a análise crítica das relações de poder entre os indivíduos e os grupos dominantes e dominados, prestando atenção à possível criação de estatutos normativos e de alteridade a uns e a outro ${ }^{28}$. Com tal disponibilidade e investimento, através de ações efetivas e emancipatórias, manifestar-se-á o genuíno interesse em agir sobre as bases que criam esustentam a discriminação e a iniquidade no universo da saúde ${ }^{28,72}$.

Este artigo segue um conjunto de propostas resultantes da literatura, das quais destacamos algumas recomendações para a melhoria das condições de saúde das lésbicas, pela via do aumento do conhecimento, do rigor da investigação e da alteração das práticas dos profissionais e do funcionamento das organizações de saúde.

Um dos princípios básicos orientadores da introdução de medidas efetivas de promoção da saúde, do bem-estar e da justiça na prestação de cuidados eno desenvolvimento de pesquisas consistenum efetivo esforço de análise e compreensão das condições de saúde das lésbicas, considerando e articulando as subjetividades com os contextos ideológico, temporal, sociocultural e psicossocial ${ }^{72}$. Sem esta complexificação e a explicitação clara e detalhada dos pressupostos conceptuais e metodológicos, aumenta o risco de confusão entre causas, associações e efeitos, no que se refere à saúde dos grupos minoritários, incluindo as lésbicas ${ }^{35}$.

Convirá, pois, ter sempre presente que os números e os cálculos não são impermeáveis a ideologias ou manipulações políticas, pelo que deveexistir reflexão prévia eclarificação de pressupostos, nomeadamente no que se refere às implicações e significados associados às nomenclaturas usadas e manipuladas pelo raciocínio epidemiológico, como seja, no caso presente, a categoria 'lésbica'. 
Para assegurar a fiabilidade dos resultados das investigações, pela via da homogeneização das participantes, e, a partir deles, fazer opções deintervenção, éimprescindível explicitar osconceitos e a taxonomia seguidos ${ }^{29,36,63}$. Em alternativa ou complementaridade, o recurso a estudos longitudinais será sempre uma possibilidade de maior aproximação à dinâmica comportamental eidentitária rel ativa à sexualidade das lésbicas e/ou das mulheres que têm atividade sexual com outras mulheres ${ }^{40}$.

A formação deve ser assumida como uma das estratégias de desenvolvimento de competências de comunicação dos profissionais, nomeadamente, para que sejam capazes de: utilizar uma linguagem neutra e não discriminatória das orientações sexuais; não impor ou prescindir de assuntos com base em presunções infundadas acerca dos comportamentos e necessidades das utentes; explicitar claramente as razões da solicitação deal guns dados clínicos, criando um clima de confiança e de garantia da confidencialidade; conhecer algumas práticas sexuais e terminologia específica; e, por fim, integrar as necessidades particulares das utentes lésbicas nas práticas de

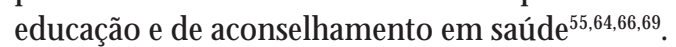

Como a relação entre profissionais e utentes ocorre em espaçosinstitucionais, estes serão mais inclusivos se consi derada a diversidade denecessidades e especificidades de quem os procura, nomeadamente, em função da orientação sexual. Para tal, as políticas e práticas profissionais e institucionais têm de ser, ao mesmo tempo, universais e particulares e promover a equidade no acesso aos cuidados de saúde, evitando o reforço dos potenciais constrangimentos pessoais, interpessoais e socioculturais.

A promoção do debatereflexivo ecrítico acerca das políticas e investimentos da organização, dos espaços físicos de espera e de atendimento, das mensagens e materiais difundidos, da comunicação informal entre profissionais e entre profissionais eutentes edo cumprimento dos princípios da confidencialidade e do humanismo constitui um investimento básico da criação de instituições apelativas e securizantes para as pessoas não heterossexuais ${ }^{66,69}$.

Como o heterossexismo se constitui como um sistema ideológico que subalterniza a homossexualidade, a prática e o pensamento orientados para a justiça social passa por anali sá-lo criticamente, apontando os el ementos de opressão institucionais e globais que o reproduzem e alimentam ${ }^{72,73}$. Esses princípios de ação, contudo, requerem também estratégias individuais e grupais de resistência que contrariem o heterossexismo ${ }^{73}$, por parte das pessoas lésbicas, que lhes permitirão agir positivamente sobre os contextos da saúde e assumir o protagonismo na gestão e promoção da sua saúde.

\section{Colaboradores}

AM M arques, JM Oliveira e C Nogueira participaram igualmente de todas as etapas de elaboração do artigo. 
Referências

1. Amâncio L. 0 género nos discursos das ciências sociais. Análise Social 2003; 38(168):687-714.

2. Oliveira JM. Orientação Sexual e Identidade de género na psicologia: notas para uma psicologia lésbica, gay, bissexual, trans e queer. In: Nogueira C, Oliveira J. M, editores. Estudo Sobre a Discriminação em Função da Orientação Sexual e da Identidade de Género. Lisboa: Comissão para a Cidadania e Igualdade de Género; 2010. p. 19-44.

3. Clarke V, Ellis SJ, Peel E, Riggs D. Lesbian Gay Bise xual Trans and Queer Psychology: an introduction. Cambridge: Cambridge University Press; 2010.

4. Carneiro N. "Homossexualidades" - uma psicologia entre ser, pertencer e participar. Porto: LivPsic; 2009

5. Garton S. Histories of Sexuality. London, New York: Routledge; 2004.

6. Katz J. The Invention of Heterosexuality. New York: Dutton; 1995.

7. M oita G. Discursos sobre a homossexualidade no contexto clínico: a homossexualidade de dois lados do espelho [tese]. Porto: Universidade do Porto; 2001.

8. Nogueira C. Um Novo Olhar Sobre as Relações Sociais de Género: perspectiva feminista crítica na psicologia social. Lisboa: Fundação Calouste Gulbenkian; 2001.

9. Haraway D. Simians, cyborgs, and women: the reinvention of nature. New York: Routledge; 1991

10. Oliveira JM, Neves S, N ogueira C, Koning M. Present but un-named: feminist liberation psychology in Portugal. Fem Psychol 2009; 19(3):494-506.

11. Foucault M. História da Sexualidade. A vontade de saber. Vol. 1. Lisboa: Relógio d'Água; 1994.

12. Butler J. Undoing Gender. New York: Routledge; 2004.

13. Cascais AF. Um nome que seja seu: dos estudos gays e lésbicos à teoria queer. In: Cascais AF, editor. Indisciplinar a Teoria: Estudos Gays, Lésbicos e Queer. Lisboa: Fenda; 2004. p. 21-65.

14. Halberstam J. Female M asculinities. Durham: Duke University Press; 1998.

15. Cohler D. Citizen, Invert, Queer: lesbianism and war in early twentieth century Britain. M inneapolis: Minnesota University Press; 2010.

16. Laqueur T. Making Sex: Body and Gender from the Greeks to Freud. Cambridge: $\mathrm{H}$ arvard U niversity Press; 1990.

17. Creed B. Lesbian bodies: tribades, tomboys and tarts. In: Grozs E, Probyn E, editoras. Sexy Bodies: the strange carnalities of feminism. New York: Routledge: 1995. p. 111-124.

18. Martin B. Femininity Played Straight: the significance of being lesbian. New York: Routledge; 1996.

19. Duggan L. Sapphic Slashers: sex, violence and American modernity. Durham: Duke University Press; 2000.

20. Weeks J. Sexuality. London: Routledge; 2003.

21. Wilton T. Lesbian Studies: Setting an agenda. London: Routledge; 1995.

22. Kinsey A, Pomeroy W, Martin C, Gebhard P. Sexual Behavior in the Human Female. Philadelphia: Saunders; 1953.

23. Hooker E. The adjustment of the male overt homosexual. J Proj Tech 1957; 21:18-31.
24. Hopkins J. The lesbian personality. Br J Psychiatry 1969; 115(529):1433-1436.

25. Mayes R, Horwitz A. DSM-III and the revolution In: the classification of mental illness. J Hist Behav Sci 2005; 41(3):249-297.

26. Boehmer U. Twenty years of public health research: inclusion of lesbian, gay, bisexual, and transgender populations. Am J Public Health 2002; 92(7):11251130.

27. Cochran SD, M ays VM, Bowen D, Gage $S$, Bybee $D$, Roberts SJ, Goldstein RS, Robison A, Rankow EJ, White J. Cancer-related risk indicators and preventive screening behaviors among lesbians and bisexual women. Am J Public Health 2001; 91(4):591-597.

28. Inhorn M C, Whittle KL. Feminism meets the 'new' epidemiologies: toward an appraisal of antifeminism biases In: epidemiological research on women's health. Soc Sci Med 2001; 53(5):553-567.

29. Epstein S. Sexualizing governance and medicaliz ing identities: the emergence of 'state-centered' LGBT health politics in the United States. Sexualities 2003; 6(2):131-171.

30. Lee R. Health care problems of lesbian, gay, bisexual, and transgender patients. West J Med 2002; 172(6): 403-408

31. M cNair RP. Lesbian health inequalities: a cultural minority issue for health professionals. M ed J Aust 2003; 178(12):643-645.

32. Mercer $\mathrm{CH}$, Bailey JV, Johnson AM, Erens B, Wellings $\mathrm{K}$, Fenton KA, Copas AJ. Women who report having sex with women British national probability data on prevalence, sexual behaviors, and health outcomes. Am J Public H ealth 2007; 97(6):1126-1133.

33. Diamant AL, Schuster, MA, Lever J. Receipt of pre ventive health care services by lesbians. Am J Prev M ed 2000; 19(3):141-148

34. Malterud K, Bjorkman M, Flatval M, Ohnstad A Thesen J, Rovtveit G. Epidemiological research on marginalized groups implies major validity challenges; lesbian health as an example. J Clin Epidimiol 2009; 62(7):703-710

35. Bakker FC, Sandfort TGM, Vanwesen beeck I, van Lindert $H$, Westert GP. Do homosexual persons use health care services more frequently than heterosexual persons: findings from a Dutch population survey. Soc Sci M ed 2006; 63(8):2022-2030.

36. Dean $L, M$ eyer $I H$, Robinson $E$, Sell RL, Sember $R$, Silenzio VB, Bowen DJ, Bradford J, Rothblum E, White J, Dunn P, Lawrence A, Wolfe D, Xavier J. Lesbian, gay, bisexual and transgender health: findings and concerns. J Gay Lesbian M ed Assoc 2000; 4(3):101-151.

37. Bailey JV, Farquhar C, Whitaker D. Sexual behaviour of lesbians and bisexual women. Sex Transm Infect 2003; 79(2):147-150.

38. H egna $\mathrm{K}$, Larsen Cl. Straightening out the queer? Same-sex experience and attraction among young people in Norway. Cult Health Sex 2007; 9(1):15-30.

39. Goldstein N. Lesbians and the medical profession: HIV/AIDS and the pursuit of visibility. In: Goldstein N, Marlowe J, editores. The Gender Politics of HIV/AIDS. New York: New York University Press; 1997. p. 86-112. 
40. Diamond L. Sexual fluidity: Understanding women's love and desire. Cambridge: Harvard University Press; 2009.

41. Aaron DJ, Chang YF, LaPorte RE. Estimating the lesbian population: a capture-recapture approach. Epidemiol Community Health 2003, 57(3):207-209.

42. Koh AS. Use of preventive health behaviors by lesbian, bisexual, and heterosexual women: questionnaire survey. West J M ed 2000; 172(6):379-384.

43. Potvin L, Gendron S, Bilodeau A, Chabot P. Integrating social theory into public health practice. Am J of Public Health 2005; 95(4):591-595.

44. Wilkinson $R, M$ armot $M$. Social Determinants of $\mathrm{H}$ ealth: the solid facts. $2^{\text {nd }}$ Edition. Copenhagen: WHO; 2003

45. King M, Semlyen J, Tai SS, Killaspy H, O sborn D, Popelyuk D, Nazareth I. A systematic review of mental disorder, suicide, and deliberate self harm in lesbian, gay and bisexual people. BM C Psychiatry 2008; 8:70.

46. Cochran SD, Sullivan JG, M ays VM. Prevalence of mental disorders, psychological distress, and mental health services use among lesbian, gay, and bisexual adults in the United States. J Consult Clin Psych 2003; 71(1):53-61.

47. Sandfort TGM, de Graaf R, Bijl R, Schnabel P. Samesex behaviour and psychiatric disorders: findings from the Netherlands mental health survey and incidence study (NEMESUS). Arch Gen Psychiatry 2001; 58(1):85-91.

48. Fredriksen-Goldsen KI, Kim HJ, Barkan SE, Balsam $\mathrm{KF}$, Mincer SL. Disparities in health-related quality of life: a comparison of lesbians and bisexual women. Am J Public Health 2010; 100(11):2255-2261.

49. Hellman RE, Sudderth L, Avery AM. Major mental illness in a sexual minority psychiatric sample. J Gay Lesbian Med Assoc 2002; 6(3/4):97-106.

50. Skidmore WC, Linsenmeier JAW, Bailey JM. Gender nonconformity and psychological distress In: lesbians and gay men. Arch Sex Behav 2006; 35(6): 685-697.

51. Balsam KF, Rothblum ED, Beauchaine TP. Victimization over the life span: a comparison of lesbian, gay, bisexual, and heterosexual siblings. J Consult Clin Psych 2005; 73(3):477-487.

52. Herrick AL, Matthews AK, Garofalo R. Health risk behaviors in an urban sample of young women who have sex with women. Journal of Lesbian Studies 2010; 14(1):80-92

53. Hughes TL, Johnson T, Wilsnack SC. Sexual assault and alcohol abuse: a comparison of lesbian and heterosexual women. J Subst A buse 2001; 13(4):515532.

54. Ponterotto J. Qualitative research in counseling psychology: a primer on research paradigms and philosophy of science. J Couns Psychol 2005; 52(2): 126-136.

55. Wilkinson S, Fish J. Understanding lesbian's health care behaviour: the case of breast self-examination. Soc Sci Med 2003: 56(2):235-245.

56. Kavanaugh-Lynch MHE, White N, Daling JR. Correlates of Lesbian Sexual Orientation and the Risk of Breast Cancer. J Gay Lesbian Med Assoc 2002; $6(3 / 4): 91-95$
57. Aaron DJ, Markovic N, Danielson ME, Honnold JA, Janosky JE, Schmidt NJ. Behavioral risk factors for disease and preventive health practices among lesbians. Am J Public Health 2001; 91(6):43-46.

58. Rankow EJ, Tessaro I. Cervical cancer risk and Papanicolaou screening in a sample of lesbian and bisexual women. J Fam Pract 1999; 47(2):139-143.

59. Weisz VK. Social justice considerations for lesbian and bisexual women's health care. J Obstet Gynecol Neonatal N urs 2009; 38(1):81-87.

60. Arend ED. The politics of invisibility: HIV-Positive women who have sex with women and their struggle for support. J Assoc N urses AIDS Care 2003; 14(6):37-47.

61. Spidsberg BD. Vulnerable and strong - lesbian women encountering maternity care. J Adv N urs 2007; 60(5):478-486

62. van Dam MAA, Koh AS, Dibble SL. Lesbian disclosure to health care providers and delay of care. J Gay Lesbian M ed Assoc 2001; 5(1):11-19.

63. King M, Warner J, Ramsay A, Johnson K, Cort C, Wright L, Blizard R, Davidson O. Mental health and quality of life of gay men and lesbians in England and Wales. Controlled, cross-sectional study. $\mathrm{Br} J$ Psychiatry 2003; 183:552-558.

64. Röndahl G, Bruhner $\mathrm{E}$, Lindhe J. Heteronormative communication with lesbian families in antenatal care, childbirth and postnatal care. J Adv N urs 2009; 65(11):2337-2344.

65. Röndahl G, Innala S, Carlsson M. Verbal and nonverbal heterosexual assumptions in nursing. J Adv Nurs 2006; 56(4):373-381.

66. Bonvicini KA, Perlin MJ. The same but different: clinician-patient communication with gay and lesbian patients. Patient Educ Cons 2003; 51(2):115-122.

67. White JC, Dull VT. Health risk factors and health seeking behavior. J Womens Health 1998; 6(1):103112.

68. Ryan CC, Bradford JB, Honhold JA. Social workers' and counselors' understanding of lesbian. J Gay Lesbian Soc Serv 1999; 41(9):1-26.

69. Perrin EC. Opportunities for Child Health Professionals. In: Perrin EC, editor. Sexual Orientation. Child and Adolescent Health Care. New York: Kuwer Academic Publishers; 2002. p. 135-160.

70. Needham BL, Austin EL. Sexual orientation, parental support, and health during the transition to young adulthood. J Youth Adolesc 2010; 39(10):1189-1198.

71. M arques AM. Género e Saúde: uma relação ainda oculta. In: Strey M N, Nogueira C, Azambuja MR, editoras. Gênero \& Saúde: diálogos ibero-brasileiros. Porto Alegre: Edipucrs; 2010. p. 35-58.

72. M atthews CR, Adams EM. Using a social justice approach to prevent mental health consequences of heterosexism. J Prim Prev 2009; 30(1):11-26.

73. Russell GM. Surviving and thriving in the midst of antigay politics. Angles 2004;7(2):1-7.

Artigo apresentado em 01/03/2012

Aprovado em 23/04/2012

Versão final apresentada em 11/05/2012 
